\section{REVIEWS Further}

Click here for quick links to Annual Reviews content online, including:

- Other articles in this volume

- Top cited articles

- Top downloaded articles

- Our comprehensive search

\section{Electrochemical Aspects of Electrospray and Laser Desorption/Ionization for Mass Spectrometry}

\section{Mélanie Abonnenc, ${ }^{1}$ Liang Qiao, ${ }^{1,2}$ BaoHong Liu, ${ }^{2}$ and Hubert H. Girault ${ }^{1}$}

\author{
${ }^{1}$ Laboratoire d'Electrochimie Physique et Analytique, Station 6, Ecole Polytechnique Fédérale \\ de Lausanne, CH-1015 Lausanne, Switzerland; email: Melanie.Abonnenc@epfl.ch, \\ Liang.Qiao@epfl.ch, Hubert.Girault@epfl.ch \\ ${ }^{2}$ Department of Chemistry, Institute of Biomedical Science, Fudan University, \\ Shanghai 200433, China; email: bhliu@fudan.edu.cn
}

\section{Key Words}

First published online as a Review in Advance on March 1, 2010

The Annual Review of Analytical Chemistry is online at anchem.annualreviews.org

This article's doi:

10.1146/annurev.anchem.111808.073740

Copyright (c) 2010 by Annual Reviews.

All rights reserved

$1936-1327 / 10 / 0719-0231 \$ 20.00$ electrochemistry, electron-transfer reaction, emitters, ion source, peptide analysis, proteomics

\begin{abstract}
Soft-ionization methods, namely electrospray ionization and laser desorption/ionization, are widely used to transfer large molecules as intact gas-phase ions either from a solution or from a solid substrate. During both processes, in-source electrochemical and photoelectrochemical reactions occur. These electrode reactions, which take place at interfaces, play important roles in influencing the ionization products, but they have received little attention. We show that having good control over both types of electrochemical reactions can lead to new analytical applications. Examples include online tagging by grafting of mass tags and in-source photooxidation of peptides.
\end{abstract}


Electrospray

ionization (ESI):

technique enabling the

transfer of ions from

the solution phase to

the gas phase through

application of an

electric field

Laser desorption/ ionization (LDI):

technique enabling the transfer of ions from a solid sample to the gas phase through laser irradiation

MALDI: matrixassisted laser desorption/ionization

Matrix-free LDI: method that does not employ a classic organic matrix, but rather a nanomaterial, semiconductor, sol-gel, or polymer

In-source reaction: reaction in the ion source, which can occur either in the plume or on the target plate

\section{INTRODUCTION}

During the past 20 years, mass spectrometry (MS) has established itself as a major technique for the analysis of large molecules and molecular complexes, particularly polymers and natural biomolecules such as proteins and nucleic acids (1-3). This spectacular development is partly based on the ability of two different soft-ionization methods, namely electrospray ionization (ESI) (4) and laser desorption/ionization (LDI) (5), to transfer sample molecules as intact gas-phase ions either from a solution or from a solid substrate. Despite these methods' widespread use in analytical chemistry and biology, studies of their fundamental aspects have not yet yielded a clear understanding of these processes, which is crucial for further developments and applications.

Electrospray is a phenomenon that has been studied as early as 1749, when Nollet (6) described the spray from a metallic orifice that was electrified electrostatically. The electrospray process was first described in the early twentieth century by Zeleny (7), who was investigating the effect of an electric field on a liquid meniscus. Although the electrospray of gas-phase polystyrene ions and their detection by MS were first reported by Dole et al. in 1968 (8), it was only in the 1980s that Yamashita \& Fenn (4) and Aleksandrov et al. (9) established electrospray as a powerful technique to softly ionize large compounds for mass analyses. Since then, ESI has become an essential technique for the study of (bio)molecules by MS, mainly because of its soft character and its ability to easily couple with separation methods such as liquid chromatography and capillary electrophoresis.

In view of the significant success of this ionization method, the electrospray process has been documented many times in recent years (10-15), but in general little attention has been paid to the inherent electrochemical aspects of this process. The coupling of a classical electrochemical cell to a mass spectrometer has been investigated (16-20) because it has the potential to allow real-time analysis of electrochemical reactions. In this review, we discuss the electrochemical reactions that take place in an electrospray emitter, along with the derived analytical implications.

Although the electrochemical aspects of ESI have long been recognized, those of LDI have only recently become a topic of interest. The use of LDI to transfer large molecules into the gas phase as intact ions was first introduced in the 1980s (5, 21); subsequently, it rapidly developed into an important soft-ionization method for MS analysis of polymers and biomolecules, such as proteins, peptides, oligonucleotides, and oligosaccharides (22). Currently, the most widely employed LDI technique is matrix-assisted laser desorption/ionization (MALDI), in which an organic matrix that can absorb laser energy is generally used to assist the ionization of sample molecules. The concept of MALDI was developed between 1984 and 1986 by Karas et al. (5), who published a summary of their technique in 1987. Alternative, matrix-free methods for LDI have also been developed. For example, in 1987 Tanaka et al. (21) analyzed proteins and polymers with laser ionization, using glycerol as a solvent and a fine metal powder as a laser-energy absorber. The first truly matrixfree LDI, introduced in 1999 by the Siuzdak group (23), is performed by placing the analyte on a semiconductor substrate of silicon. This technique is now known as desorption/ionization on porous silicon (DIOS) (24).

The mechanisms for LDI are still not completely understood. During this nanosecond-long photoelectrochemical process, a plume of sample, matrix, electrons, and radicals is generated by laser irradiation. In this plume, ion-ion reactions and ion-molecule reactions occur, in turn generating the final products for MS detection (25). Meanwhile, when LDI is coupled with timeof-flight (TOF) mass spectrometers, a voltage is usually applied shortly after the laser pulse to extract the ions; the target plate acts as a de facto electrode (26). This review also describes the electrochemical aspects of in-source redox reactions that occur during LDI, along with the derived analytical implications. 


\section{ELECTROSPRAY IONIZATION MASS SPECTROMETRY}

\subsection{Electrochemical Aspects of the Taylor Cone}

The general electrospray process is depicted in Figure 1. When a potential difference is applied between a solution flowing through a capillary and a counterelectrode placed in the outside air facing the capillary outlet, a fine mist of charged droplets is emitted, leading to the formation of gas-phase ions for subsequent mass analysis. The electrospray process can be operated either in a positive mode or in a negative mode, wherein a positive or negative potential difference generates the formation of gas-phase cations or anions, respectively.

During electrospray, the current is carried by ionic conductivity in the solution and by gasphase droplets and ions to the mass spectrometer. One electrode is in contact with the solution; the other is the ion detector of the spectrometer and is usually combined with an electron multiplier. The solution-air interface at the emitter tip is polarized. In 1964, Taylor (27) showed that the shape of this interface under the application of a potential difference between the two electrodes

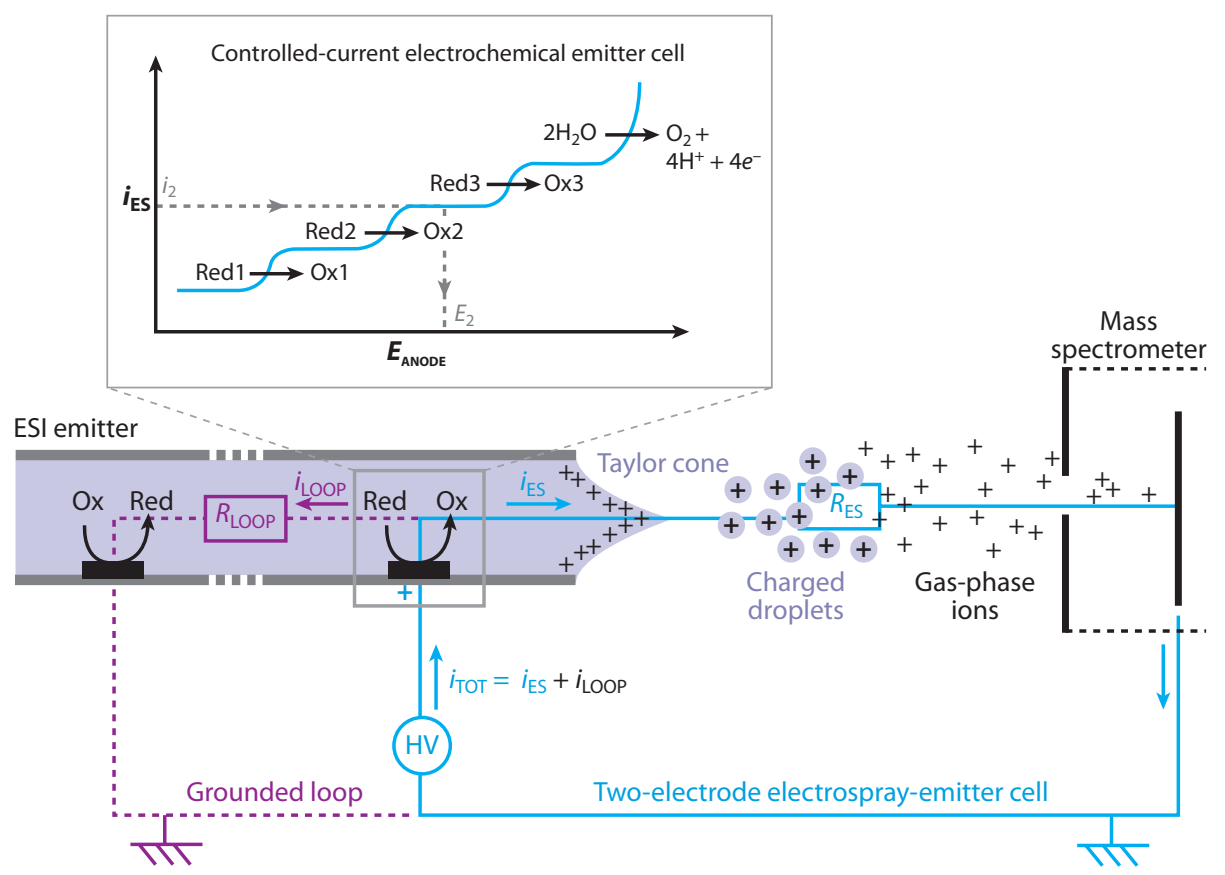

Figure 1

Scheme of the electrospray ionization (ESI) process. A positive high voltage (HV) is applied between the electrode in solution and a counterelectrode (i.e., the mass spectrometer). The ESI process is equivalent to an electrical circuit (blue loop), which acts as a two-electrode electrospray-emitter cell. At the metal-solution interface, heterogeneous electron-transfer reactions controlled by the current take place to ensure charge balance in the capillary. The total electrospray current $\left(i_{\mathrm{TOT}}\right)$ is the sum of the different oxidation processes (inset). The potential at the metal-solution interface $\left(E_{\mathrm{ANODE}}\right)$ in the electrospray emitter ultimately determines whether a particular species undergoes redox reactions under steady-state current conditions. In the presence of a grounded loop (purple loop) upstream of the electrospray-emitter electrode, the $i_{\text {TOT }}$ through the capillary represents the sum of the electrospray current $\left(i_{\mathrm{ES}}\right)$ and the current in the grounded loop $\left(i_{\text {LOOP }}\right)$. The upstream-grounded electrode therefore acts as a cathode wherein electrochemical reactions occur. $R_{\mathrm{ES}}$ and $R_{\mathrm{LOOP}}$ are the resistances of the two-electrode electrospray-emitter cell and the grounded extra loop, respectively. 
tends to be conical; this shape is now referred to as the Taylor cone. Charging the electrolyte-air interface therefore results in a potential drop within the solution side that can be described by the Gouy-Chapman model of diffuse double layers. In other words, the potential drop in the solution side is less than $1 \mathrm{~V}$, and it takes place over a distance defined by the Debye length of the electrolyte, specifically a few nanometers at most. The relationship between the surface-charge density $\sigma$ on the solution side of the interface and the electric field $\boldsymbol{E}$ just outside the interface is given by Gauss's law, $\boldsymbol{E}=\sigma / \varepsilon_{0} \hat{\boldsymbol{n}}$, where $\hat{\boldsymbol{n}}$ represents the unit vector normal to the surface and $\varepsilon_{0}$ refers to the vacuum permittivity. This relationship shows that a surface-charge density of $1 \mu \mathrm{C} \mathrm{m}^{-2}$ corresponds to a field of $1 \mathrm{kV} \mathrm{cm}^{-1}$. In comparison, the charge on a polarized mercury electrode in solution is of the order of $100 \mathrm{mC} \mathrm{m}^{-2}$.

According to Eyring et al.'s (28) early work on electrified metallic points, if the shape of the cone can be assumed to be a hyperboloid, then the equipotential lines are hyperbolic, and the ionic charge accumulation reaches a maximum value at the tip. Because, according to Lippmann's electrocapillary theory (29), the surface tension decreases as the ionic surface-charge density increases, the surface tension holding the cone is lowest at the tip. This is why, when the electric field reaches a critical value, the interface breaks at the tip and small droplets are emitted.

Once in the gas phase, the charged droplets are subjected to evaporation and fission events, leading to the formation of gas-phase ions. The electrochemical aspects of a charged droplet are also interesting. Two theories for the generation of gas-phase ions are usually considered: the charge-residue model proposed by Dole and colleagues $(8,30)$ and the ion-evaporation model proposed by Iribarne \& Thomson (31). Concerning electrochemistry at liquid-liquid interfaces, Marcus (32) proposed that ion-transfer reactions from an aqueous phase to an organic phase occur according to the formation of so-called hernias formed during the capillary motion occurring at the interface. This mechanism is analogous to the ion-evaporation model. However, the Marcus model suggests that ion evaporation is more a consequence of the interfacial dynamics than a consequence of electrostatic repulsion within the Gouy-Chapman diffuse layer.

\subsection{Electrospray Viewed as a Two-Electrode Electrochemical Cell}

The electrode that applies the potential difference with respect to the gas phase is, by definition, in contact with the electrolyte solution. When a current flows through the electrospray emitter, electrochemical reactions occur both at the metal-solution interface and at the ion detector. In positive-ionization mode, the electrode acts as an anode and is the locus of oxidation reactions. Conversely, in negative-ionization mode, the electrode acts as a cathode and is the locus of reduction reactions.

Heterogeneous electron-transfer reactions were experimentally observed in 1991 by Blades et al. (33), who observed electrogenerated ions through use of zinc capillaries. They observed that the $\mathrm{Zn}^{2+}$ concentration matched the concentration expected on the basis of the electrospray current measured when using a zinc-capillary emitter tip. The authors observed similar results for $\mathrm{Fe}^{2+}$ ions when they used a stainless-steel capillary. The extent of the reaction that occurs at the electrode can be determined by the magnitude of the faradaic current.

The electrical circuit of the electrospray process (34) is depicted in Figure 1. If we apply a potential drop $(\Delta \mathrm{V})$ between the electrode in solution, and if the mass spectrometer acts as a counterelectrode in the gas phase, the current is constant throughout the circuit and almost all the potential drops occur in the gas phase. According to Ohm's law, the resistance $\left(R_{\mathrm{ES}}\right)$ between the two electrodes is the sum of three resistances: those of the electrolyte solution, the solution-air interface, and the gas phase. The smallest of the three is that of the solution. Therefore, from an electrochemical standpoint, the electrospray operates a two-electrode cell; in this cell, the 
interface and the gas-phase resistance limit the current, which in normal operating conditions is at submicroampere levels. As a result, the potential drop in the solution itself is negligible, and those at the electrode-solution and solution-air interfaces are usually no more than $1 \mathrm{~V}$. Van Berkel \& Zhou (35) were the first to characterize the electrospray process as a current-controlled electrochemical cell.

The potential at the metal-solution interface in the electrospray emitter ultimately determines whether or not a particular species undergoes redox reactions. It is a function of the total electrospray current $\left(i_{\mathrm{TOT}}\right)$, the redox potentials and the concentration of the various species present in the solution, the metal-electrode properties, the mass transfer to the electrode, and the kinetics of the charge-transfer reactions. Assuming there is a steady-state current, the oxidation current can be described as the sum of the different oxidation processes: The species with the lowest redox potentials are oxidized first until the solvent becomes oxidized (Figure 1). Because heterogeneous electrochemical reactions are inherent to the electrospray process, they must be controlled. In some cases they can be used to carry out specific reactions for analytical purposes.

\subsection{Electrochemical Alteration of the Solution Composition}

Electrode reactions may alter the composition of the solution. Van Berkel et al. (36) highlighted the electrochemically induced change of the solution composition during the electrospray process under certain conditions. As a result of the electrolytic oxidation of water (in positive-ionization mode), a significant $\mathrm{pH}$ decrease of the bulk solution of up to four units was observed. This modification of solution $\mathrm{pH}$ may have important analytical implications. For instance, modification of the protein conformation was observed through a shift of the protein charge-state distribution, which occurs by MS. Further evidence, observed in the presence of a grounded loop upstream of the emitter electrode (see Figure 1), was reported by Konermann et al. (37). The addition of an extra electrical loop can significantly enhance the $i_{\text {TOT }}$ passing through the electrode in comparison with the current limited by the gas-phase resistance, and subsequently it can generate more oxidation products. Konermann et al. observed online acidification of the bulk solution, which led to protein unfolding. In these two examples, the alteration of the solution composition had dramatic effects on the analyte chemical stability. In negative-ionization mode, reduction of water was observed to aid the ionization of ubiquitin protein by rendering the solution more basic (38).

\subsection{Enhanced Analyte Ionization}

Electrode reactions can be employed to enhance the ionization of analytes. By definition, ESI-MS enables both the transfer of ions from the liquid phase to the gas phase and their subsequent analysis by MS according to their mass-to-charge ratio. Therefore, this method is unsuitable for the study of neutral molecules. Nevertheless, easily oxidized compounds can be ionized through electrochemical oxidation and become detectable by ESI-MS analysis. The ESI-MS analysis of alkyl-substituted metalloporphyrins, which are a type of polycyclic aromatic hydrocarbon, was reported by Van Berkel et al. (39). Xu et al. (40) studied the electrochemical oxidation and nucleophilic addition reactions of metallocenes during the electrospray process. The stability of the radical cations (or anions) in the solvent is an important prerequisite for their detection by MS. In such experiments, radical cation- or radical anion-solvent reactions that can interfere with the analysis should be minimized, so the solvent system must be chosen carefully. Ochran \& Konermann (41) reported the enhancement of ferrocene oxidation by the presence of a grounded loop downstream of the electrospray emitter. 


\subsection{Online Electrochemical Reactors}

The electrochemical properties of the ESI can be used to initiate homogeneous reactions in the emitter. Over the past few years, our laboratory has extensively investigated online electrochemical tagging of biomolecules. By taking advantage of the electrochemical properties of the electrospray, our group tagged cysteine residues in peptides and proteins through use of substituted hydroquinones $(42,43)$. The electrochemical tagging of cysteines was accomplished by in situ oxidation of hydroquinone to benzoquinone, followed by its addition to the peptides during ESI-MS. The potential of this online electrochemical tagging has been demonstrated with microfabricated electrospray emitters, with which instrumental parameters (e.g., current density at the electrospray electrode and residence time of analytes and chemical probes) can be tailored and controlled. The influence of the tagging-rate constant, as well as the impact of the probe and target concentrations, was investigated numerically for single and consecutive tagging reactions in a microchannel (Figure 2) (44). This method was successfully used to count online cysteine residues in peptides, which yields relevant information for definitively identifying proteins by peptide mass fingerprinting (45). Using the same approach to probe cysteine reactivity in proteins (46), we performed experiments with both native and reduced proteins that highlighted the strong influence of cysteine-site reactivity on tagging efficiency.

Recently, Van Berkel et al. (47) inserted a liquid microjunction surface-sampling probe into a two-electrode electrochemical cell through use of a conductive surface; the probe was composed of two electrodes with an appropriate battery-powered circuit. With this novel approach, the authors demonstrated efficient modification of cysteine residues, both in solution and sampled from a surface, using electrochemical tagging involving hydroquinone tags.
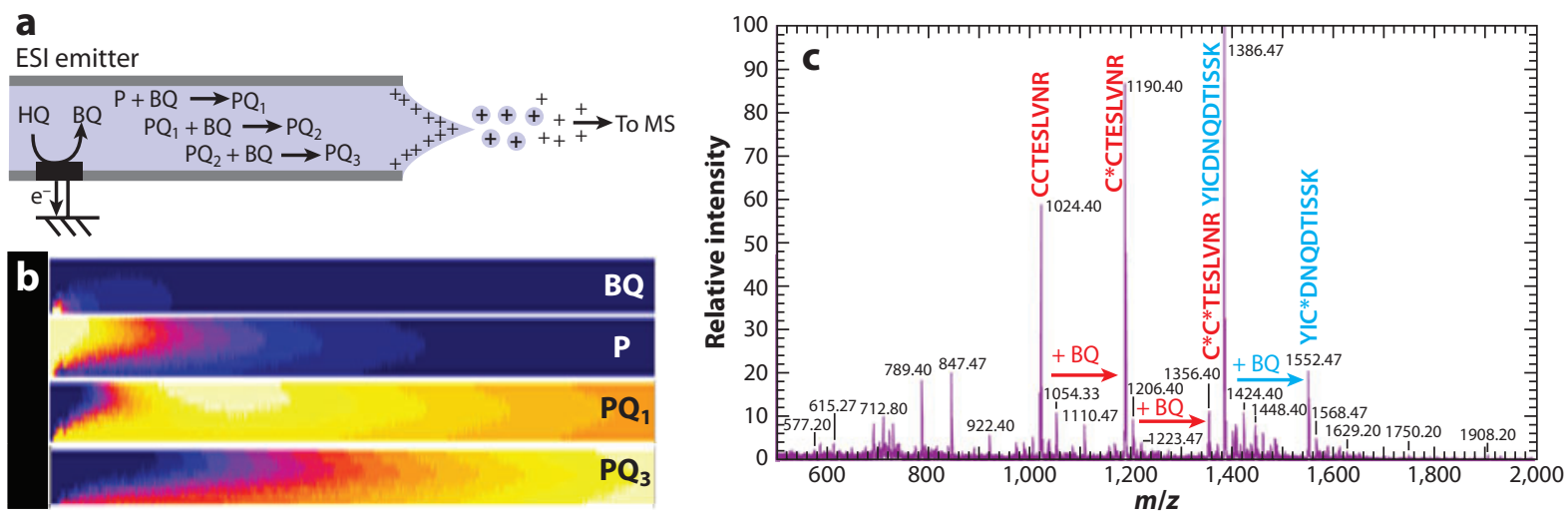

Figure 2

Scheme of in situ oxidation of hydroquinone (HQ) to benzoquinone (BQ) for online cysteinyl peptide tagging in electrospray ionization mass spectrometry (ESI-MS). (a) Capillary tagging. (b) Concentration isovalues for the BQ tag, the peptide P, the once-tagged peptide PQ1, and the thrice-tagged peptide PQ3 along the ESI-emitter microchip. (c) Mass spectrum of two tryptic peptides of bovine serum albumin protein. The two peptides contain one and two cysteines, respectively. 


\subsection{Sacrificial Metallic Anodes}

The characteristics of the electrospray electrode in terms of metal composition should be considered carefully from an electrochemical standpoint. In positive-ionization mode, the emitter electrode acts as an anode. When the electrode is made of transition metal with a relatively low redox potential, generation of metal ions may occur by electrodissolution of the anode. Electrode corrosion at the ESI emitter has been studied ever since the early demonstration by Blades et al. (33) of metal-ion electrogeneration from a metallic capillary tip. Van Berkel (48) has developed an electrospray-photodiode array system with which to probe the electrolytic corrosion of a stainless-steel emitter. In contrast to $\mathrm{Fe}^{2+}$ ions, few or no $\mathrm{Fe}^{3+}$ ions were found, suggesting that some analyte-oxidation products observed in ESI mass spectra may arise from reaction with electrogenerated $\mathrm{Fe}^{3+}$ ions rather than from direct electrochemical oxidation at the electrode. In another study, Van Berkel and colleagues (49) used wire-in-a-capillary, bulk-loaded nanoelectrospray emitters to study different electrode materials (e.g., platinum, stainless steel, copper, and iron). In this paper, the authors discussed the influence of solvent oxidation, emitter-electrode corrosion, and analyte oxidation on the time-dependent solution composition and on the resulting mass spectra. Unlike in the pumped system, an accumulation of electrogenerated products occurs in bulk-loaded, wire-in-a-capillary nanoelectrospray emitters, leading to a significant time delay between the products' formation and their detection in the gas phase.

Another interesting feature of emitter-electrode corrosion was presented by Van Berkel \& Kertesz (50), who showed that a copper capillary emitter can be used as a redox buffer in positiveionization mode. The electrogeneration of copper ions at the anode maintains the interfacial potential at this electrode near the equilibrium potential for the copper-corrosion process $\left(E^{\circ}=\right.$ $0.34 \mathrm{~V}$ versus standard hydrogen electrode), which allows control over the electrochemical reactions that take place at this electrode. Therefore, the oxidation of $N$-phenyl-1,4-phenylenediamine to $N$-phenyl-1,4-phenylenediimine, as was observed with a stainless-steel capillary, was prevented through use of a copper capillary. The authors also found that $N$-phenyl-1,4-phenylenediimine can be reduced in the copper capillary emitter in positive-ionization mode, demonstrating the presence of $\mathrm{Cu}(\mathrm{I})$ ions. In this paper (50), the authors also discussed the advantages of using electrochemically introduced metal ions to study metal-ligand complex chemistry or to ionize particular molecules through metal-analyte cationization. Doing so eliminates the need for metal salts that can generate analyte signal suppression induced by anions (51). Moreover, in contrast with electrogenerated metal ions, concentrated metal ions introduced in solution can carry most of the electrospray current that leads to signal-suppression effects (52).

From a clinical standpoint, the study of metal-analyte complexation is of great interest. Indeed, metal ions are involved in several pathological disorders and diseases. Studies of metal-biomolecule interactions may therefore contribute to our understanding of biological processes involving metals. Our laboratory has investigated the use of an actively oxidizing anode for the study of metal ion-peptide complexation. In one experiment, online peptide complexation with electrogenerated transition-metal ions from sacrificial electrodes was carried out in an electrospray-emitter chip (53). Transition-metal (e.g., copper, zinc, nickel, iron, and silver) electrodes were used to study online complexation with model peptides, demonstrating the efficiency of a system that does not require the use of metallic salts. Furthermore, this study highlighted the benefits of using a microspray interface, which provides enhanced mass transport due to its small size and therefore increases the yield of possible reactions, particularly complex formation. Of all the electrode materials tested, copper and zinc were the best suited for the generation of transition-metal cations, and the subsequent online chelation to peptides, due to their redox potentials and solvation time. 
WE: working

electrode

Electrochemical generation of $\mathrm{Cu}(\mathrm{I})$ and $\mathrm{Cu}(\mathrm{II})$ ions via a sacrificial copper electrode has been studied in greater detail. For instance, electrogeneration of $\mathrm{Cu}(\mathrm{I})$ complexes in solution following copper oxidation has been demonstrated (54). In this experiment, copper-peptide interactions were investigated as a function of the copper-oxidation state. Electrogenerated $\mathrm{Cu}(\mathrm{I})$ and $\mathrm{Cu}$ (II) ions were found to anchor to residues such as arginine and histidine, respectively (55). Sacrificial copper electrodes were also used to demonstrate oxidation of cysteine-containing peptides, a process that is catalyzed by copper ions. These reactions indicate the formation of intra- and intermolecular bridges. The influence of the electrode material on cysteine oxidation was also demonstrated both chemically and electrochemically. The oxidation products found at a zinc electrode differed from those obtained with a platinum electrode. These results can be explained by recognizing that zinc has a very low redox potential, whereas platinum is inert with respect to its own electrooxidation.

Sacrificial electrodes have also been employed for the mass tagging of phosphopeptides with a dual-channel microsprayer (56). The interaction between phosphopeptides and a dinuclear zinc complex, either synthesized in vitro or electrogenerated in situ with a sacrificial zinc electrode, was studied via MS. Phosphopeptides and peptides were infused from one channel of the microsprayer, and the electrogeneration of the tag (based on a commercial ligand) was achieved in the second channel (Figure 3).

\subsection{Controlling the Electrochemical Reactions}

As mentioned above, uncontrolled electrochemical reactions in an electrospray-emitter cell may engender analytical complications. Some ways to control heterogeneous reactions at the electrode have been proposed. First, the geometrical parameters of the electrospray source should be carefully considered to limit mass transfer to the electrode, as well as the applied solution flow rate through the emitter. Second, the use of an appropriate metal electrode or redox buffers can promote a specific electrochemical reaction at the electrode.

A recent approach proposed by Van Berkel et al. (57) involves a battery-powered, controlledcurrent electrospray-emitter cell. In this two-electrode system, one of the two electrodes is used as a working electrode (WE), and the other acts simultaneously as a quasi-reference and auxiliary electrode. The system allows limited control over the WE potential because the potential of the quasi-reference electrode is not well defined. Such modification of a standard electrospray emitter introduces an extra current loop into the system in addition to the upstream current loop and the electrospray current loop. The measured WE and auxiliary electrode currents are the sum of these individual partial currents superimposed on the current produced by the battery $\left(i_{\mathrm{BAT}}\right)$. Analyte electrochemistry takes place only at the porous flow-through $\mathrm{WE}$, regardless of the current magnitude and polarity at the auxiliary electrodes, because of the small total surface area of the four linked auxiliary electrodes. As a proof of concept, enhanced analyte (e.g., reserpine) oxidation or reduction at the WE was demonstrated, as was the ability to turn off analyte oxidation in positive mode (or reduction in negative mode). Also, by controlling the magnitude and polarity of the current at the large surface area WE rather than controlling the WE potential directly, the investigators (57) demonstrated the ability to reduce analytes (i.e., methylene blue) in positive mode and oxidize in negative mode.

Another alternative is to modify the electrospray-emitter source so that it can be operated as a controlled-potential electrochemical cell. In such cases, the electrical circuit is composed of a potentiostat, an auxiliary, a reference electrode, and a WE embedded into the ESI source and parallel to the counterelectrode (i.e., the mass spectrometer). Cole and colleagues (58) first proposed such a cell, in which an annular three-electrode electrochemical cell—containing a 

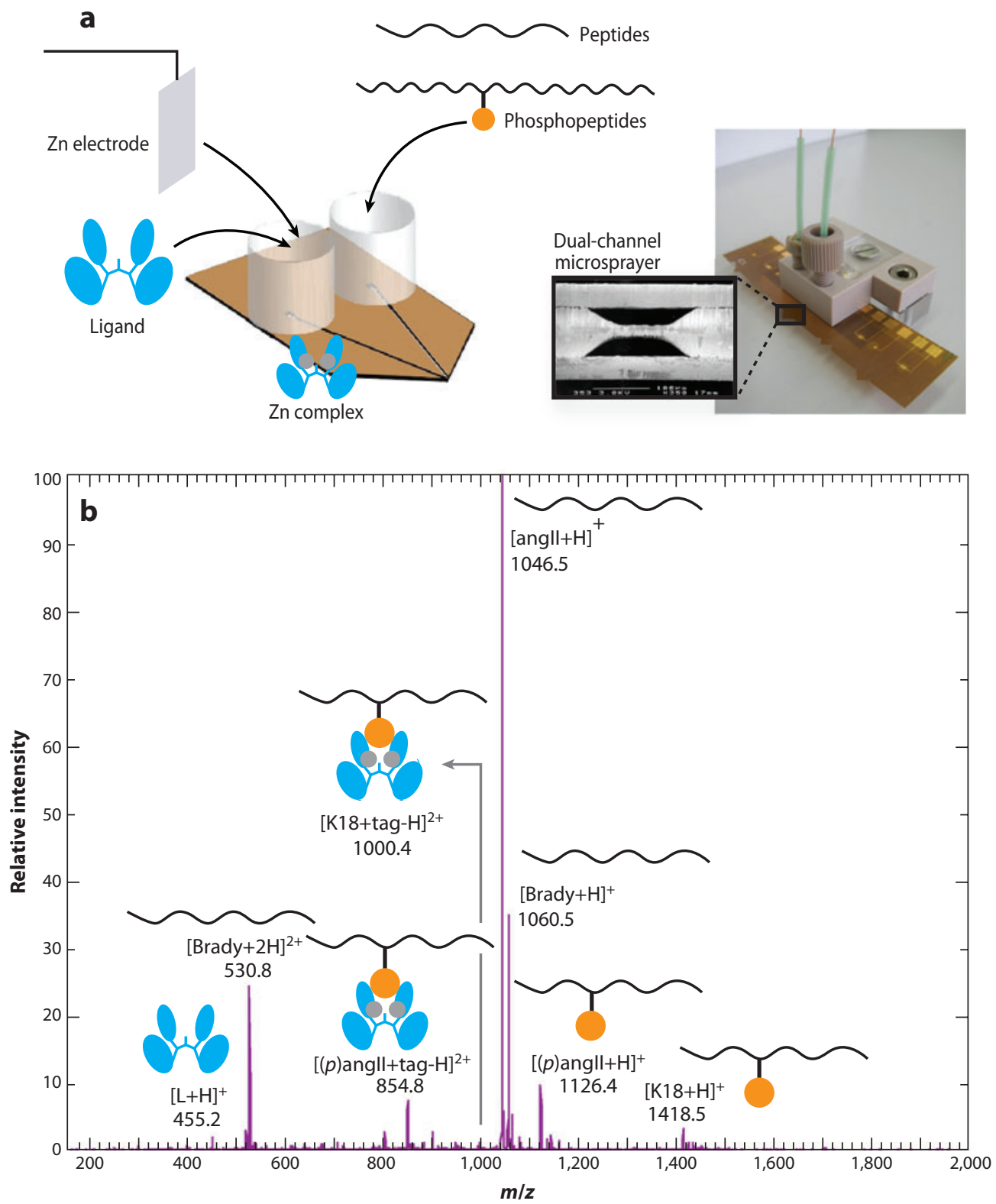

Figure 3

(a) Dual-channel microsprayer with a sacrificial zinc electrode for online characterization of phosphopeptides. One channel contains a mixture of nonphosphorylated [bradykinin (brady) and angiotensin II (angII)] and phosphorylated [(p)angII, keratin (K) 8 and 18] peptides. The other channel contains the activated $\mathrm{Zn} \operatorname{tag}(\mathrm{L})$. Peptide tagging occurs inside the Taylor cone. (b) Mass spectrum of the online phosphopeptide labeling result within the dual channel. 
In-plume reaction: reaction in the $\mathrm{LDI}$ plume; normally completed within several hundred nanoseconds following laser irradiation
WE, an auxiliary electrode, and a reference electrode-was incorporated into the electrospray probe. The authors identified ionic intermediates (radicals) and products generated from anodic oxidation and ensuing solution-phase reactions. The key feature of their device was the short distance between the WE and the Taylor cone that minimizes the time between the electrogeneration of ions and their release into the gas phase and subsequent detection by MS. Finally, Van Berkel et al. $(59,60)$ reported an electrospray-emitter cell that incorporated either a planar flow-through or a porous flow-through WE. Because the mass transport of analytes to the auxiliary electrode in the electrospray-emitter cell is critical, one must reduce the number of undesired electrochemical reactions at this electrode by $(a)$ removing the auxiliary electrode from direct contact with the analyte in the flow stream or $(b)$ limiting mass transport to this electrode. One option is to place the auxiliary electrode in a port that is remote from the main analyte solvent stream. Alternatively, the area of the auxiliary electrode should be made as small as possible so as to limit the number of electrochemical reactions at these electrodes. Finally, the authors demonstrated enhanced mass transfer to the WE when they used a porous flow-through WE.

\section{LASER DESORPTION/IONIZATION MASS SPECTROMETRY}

Whereas the electrochemical aspects of ESI have been studied for many years, those of LDI have attracted less interest. In this section, we focus on some electrochemical aspects of MALDI and matrix-free LDI techniques.

\subsection{Matrix-Assisted Laser Desorption/Ionization}

In MALDI, the sample to be analyzed, together with an organic matrix, is deposited on a conductive plate. Upon laser irradiation, a photochemical process combining photoablation and photoionization takes place, and the ions produced are accelerated to a mass detector through application of an electric field between the plate and the detector. The reaction mechanisms that occur during the MALDI process are the subject of ongoing debates, but it is widely accepted that the matrix plays an important role during both desorption and ionization.

The matrices employed in MALDI are usually organic species that can absorb laser energy and disperse sample molecules. Some common matrices, such as 2,5-dihydroxybenzoic acid (DHB), $\alpha$-cyano-4-hydroxy-transcinnamic acid, and sinapinic acid, are particularly suited to nitrogen $(337 \mathrm{~nm})$ and Nd-YAG (355 nm) lasers (22). The analytes are usually dissolved in a matrix-solvent mixture (typically consisting of a matrix-to-analyte ratio of 1000 to 1 or larger) and deposited on the target plate for crystallization. Some researchers have suggested that ions are preformed in the matrix crystal and then desorbed as matrix ion pairs (61) into the gas phase by laser irradiation $(25,62,63)$. Active species, such as electrons and radicals, are also generated during the MALDI process (25). Therefore, secondary reactions among analytes, matrices, and active species can take place in the plume, ultimately leading to the generation of sample ions. For mass spectrometers equipped with a TOF analyzer, these sample ions are extracted by a delayed-potential pulse into the TOF tube, and the counterions are driven back to the target plate. Because an ion current arises from the application of the voltage pulse, an electrochemical reaction must occur at the metallic plate-matrix interface to ensure the continuity of the current (Figure 4). Although much attention has been paid to the in-plume charge-transfer reactions, very few studies have investigated the electrode reactions that take place at the target plate, for instance, the fact that the matrix can be considered as a proton conductor. 


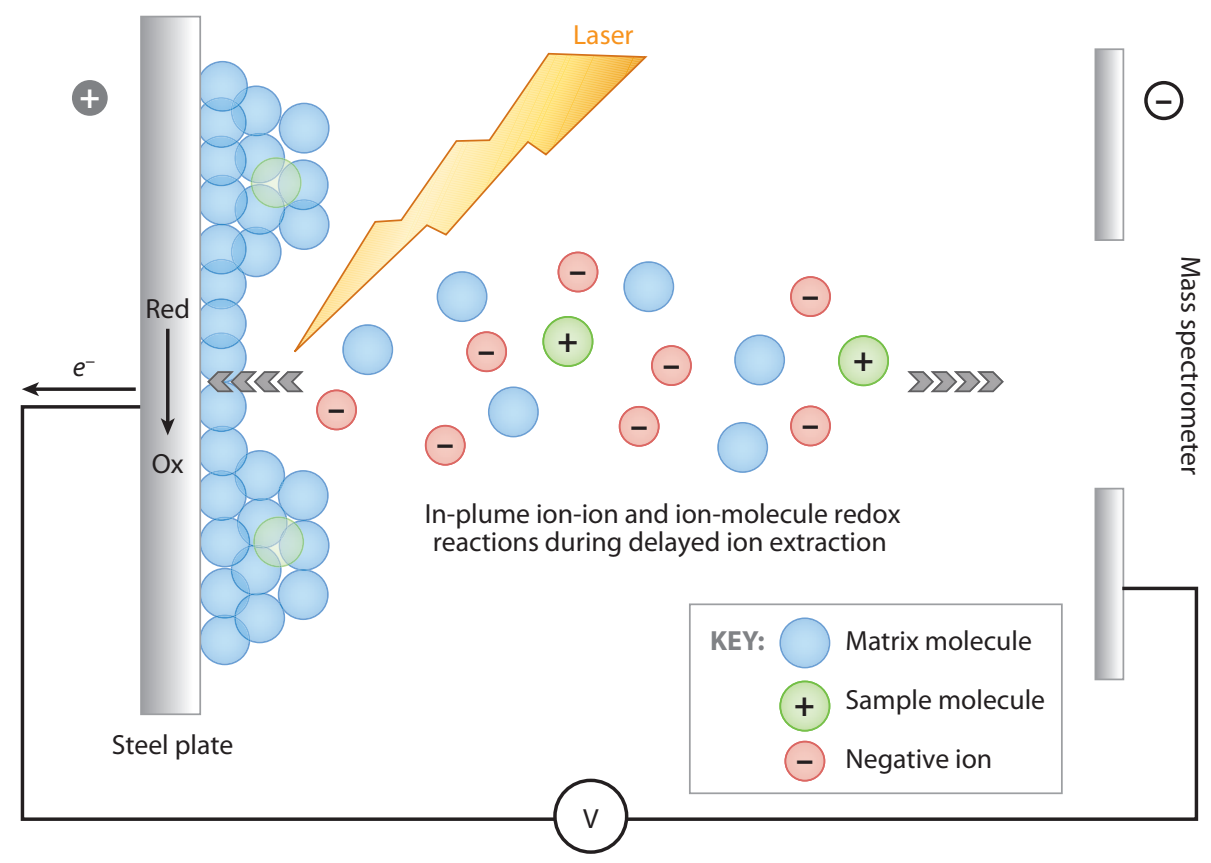

Figure 4

Schematic representation of a matrix-assisted laser desorption/ionization process, comprising in-plume reduction and on-plate electrode reaction, in positive-ionization mode.

\subsection{Electron Generation During Matrix-Assisted Laser Desorption/Ionization}

During MALDI, analyte reduction is often observed. It has been reported that the $\mathrm{NO}_{2}$ moiety of nitrotyrosine can be partially converted in source to $\mathrm{NH}_{2}(64,65)$ and that S-nitrosylated cysteine residue can decompose to cysteine (66). These reduction processes are believed to be initiated by photoelectrons generated by laser irradiation from the matrix-covered substrate. Indeed, due to the presence of photoelectrons in the MALDI ion source, reduction reactions often take place in the plume. According to their charge, parts of the reduction products are extracted toward the detector, whereas those of opposite charge are driven back to the target plate (Figure 4).

The photoelectrons generated during MALDI can arise either from photoionization of the matrix itself or from photoejection from the metal substrate, particularly in negative-ionization mode. In 2002 and 2003, Zenobi and colleagues (67-69) developed a method for detecting electrons generated during MALDI. To evaluate the presence of electrons, the authors added $\mathrm{SF}_{6}$, which has a high $\left(1 \times 10^{-15} \mathrm{~cm}^{2}\right)$ cross-section capture for low-energy electrons, to the vacuum chamber as an electron scavenger. Thus, the amount of $\mathrm{SF}_{6}{ }^{-}$was used to evaluate the number of electrons generated in MALDI. By comparing four different target plates consisting of a bare metal surface, a metal surface covered with either a thin or a thick layer of matrix, and nonmetallic insulating plates, the authors found that metal surfaces covered with a thin layer of matrix generate more electrons than do the other target plates, indicating that electrons are formed mainly at the metal-matrix interface through a photoelectrochemical process (68). Because the work function of the metals studied $\left(\Phi_{\text {stainless-steel }}=4.2-4.7 \mathrm{eV}\right)$ is greater than the photon energy $E=3.68 \mathrm{eV}$ (at $\lambda=337 \mathrm{~nm}$ ) or $E=3.49 \mathrm{eV}$ (at $\lambda=355 \mathrm{~nm}$ ), it has been proposed that the presence of a thin layer of organic material shifts the Fermi level of the metal and decreases its 
work function $(67,70)$. Further evidence for this hypothesis was obtained through a comparison of the energy of photoelectrons emitted from gold $\left(\Phi_{\mathrm{Au}}=5.1 \mathrm{eV}\right)$ and from stainless steel: $\mathrm{A} \sim 0.4-\mathrm{eV}$ difference in kinetic energy was obtained, which accords well with the work-function difference between these two materials (67). Electrochemically speaking, the target plate acts as an anode in positive-ionization mode and as a cathode in negative-ionization mode. This means that in the former case the Fermi level decreases as the metal-matrix interface becomes polarized [metal positively charged versus the matrix (71)] and therefore that the photoejection becomes more difficult. Conversely, in negative-ionization mode, the Fermi level increases when there are excess electrons at the metal surface, and photoejection is facilitated. The metal-matrix interface should remain polarized after the application of the potential pulse, and the shift of the Fermi level should remain until the next laser pulse. Although the two pulses of light and the electric field are not concurrent, the MALDI process can be considered as a photoelectrochemical process.

\subsection{In-Plume Charge-Transfer Reactions}

Photoelectrons in the ionization plume can be captured by electron-acceptor species, inducing insource reductive reactions. Because neutral matrix molecules are the most abundant species in the plume, electrons are expected to react primarily with the matrix, thereby forming matrix anions and hydrogen atoms (67) that can further react with sample ions. As a result of these MALDI in-plume charge-transfer reactions, neutralization of multicharged ions (72), reduction of $\mathrm{Cu}$ (II) and dyes $(73,74)$, and peptide in-source decay (ISD) (75) can be observed.

An important characteristic of MALDI ionization is that it generates mostly singly charged ions, especially for low- or mid-molecular weight samples $(<5000 \mathrm{Da})$; this point has been the subject of intense debate. In 2000, the Karas group (62) argued that singly charged molecular ions are lucky survivors from in-plume neutralization with electrons. The authors assumed that the charge state of the analytes within the matrix crystals is roughly conserved and is acquired in solution according to the $\mathrm{pH}$. Thus, sample ions, including both singly charged ions and many multicharged ions, are largely preformed in the solid matrix on the target plate. Through laser irradiation, clusters of matrix and sample molecules, together with charges, are generated and expanded into the plume. Because of the intense electric affinity, highly charged clusters are believed to be unable to survive and undergo charge reductions to the states of one and zero by neutralization with electrons or matrix anions in positive mode and with protonated matrices in negative mode, respectively. This hypothesis was partially proved by Zenobi and colleagues (72), who controlled electron generation during the MALDI process. By using a nonmetallic plate to inhibit photoelectron formation, the authors found enhanced positive-ion signals and higher intensities of multicharged-ion distribution.

Structural analysis of synthetic polymers by MALDI-MS often requires the adduction of metal ions, such as $\mathrm{Cu}(\mathrm{II})$, to assist in ionization (76). However, molecules cationized by copper always have a majority of $\mathrm{Cu}(\mathrm{I})$, although only $\mathrm{Cu}(\mathrm{II})$ salts are added to the sample. Otherwise, the adducts of multivalent metal ions would be detected as singly charged ions formed from deprotonation (77-80). Such in-source reduction of $\mathrm{Cu}(\mathrm{II})$ has been observed many times and was discussed in detail in 2003 (73). The authors of this paper investigated the ionization properties of $\mathrm{CuCl}_{2}$ and compared the results from three different conditions: (a) no matrix and no free electrons, $(b)$ no matrix but many free electrons, and $(c)$ matrix present but no free electrons. The results indicated that free-electron capture is the dominant mechanism for the reduction of $\mathrm{Cu}$ (II) and that $\mathrm{Cu}(\mathrm{II})$ can also be reduced in the absence of free electrons by gas-phase charge exchange with matrix molecules. 
In-source reductions have also been observed for organic dyes $(74,81)$. Using MALDI, Wada and colleagues (74) analyzed methylene blue, Janus green B, crystal violet, and rhodamine B and found that peaks for $[M+1]$ and $[M+2]$ relative to the $[M]$ peak were significantly increased in comparison to those for theoretical isotopic distribution, demonstrating reduction of $(\mathrm{M}) \mathrm{H}^{+}$and $(\mathrm{MH}) \mathrm{H}^{+}$. This reducing effect correlated with the reduction potentials of the analytes. Indeed, following the addition of $\mathrm{Cu}$ (II) into these dye systems, reduction of dyes was greatly inhibited while the production of $\mathrm{Cu}(\mathrm{I})$ was enhanced, consistent with $\mathrm{Cu}(\mathrm{I})$ 's relatively lower reduction potential. The authors argued that this reduction resulted from charge transfer between analyte and matrix because the reaction efficiency was increased for a larger matrix/dye ratio, which seems to contradict the conclusion obtained from the $\mathrm{Cu}(\mathrm{II})$ in-plume reduction.

\subsection{Peptide In-Source Decay}

An important and analytically useful type of in-source reaction is peptide ISD. Although MALDI is considered as a soft-ionization technique that usually produces intact, singly charged biomolecular ions, a significant degree of decay can be observed along the peptide or protein backbone, as in postsource decay (PSD) and ISD. ISD was first observed and applied to the structure analysis of peptides and proteins in 1995 (75). Typically, it occurs less than 100 ns after the desorption/ionization step in the ion source $(82,83)$ and results in the cleavage of the $N-C_{\alpha}$ bond of the peptide backbone, producing $c$ - and $z$-fragment types (Figure 5) (83). The matrix employed is a key factor influencing the decay efficiency. DHB is usually a suitable matrix for ISD, whereas the widely used MALDI matrix $\alpha$-cyano-4-hydroxycinnamic acid is inefficient. Recently, a new reductive matrix, 1,5-diaminonaphthalene, which is known for its hydrogen radical-donating ability, was used to perform high-quality ISD (84).

Compared with PSD and other MS/MS fragmentation methods—such as collision-activated dissociation, electron-transfer dissociation, and electron-capture dissociation (ECD)-ISD has the advantage of being theoretically unlimited by sample mass. This technique thus shows great promise for use in top-down protein-sequencing strategies, which may lead to new strategies for proteome research (84). Also, labile posttranslational modifications such as phosphorylation can be well preserved during the ISD process (84-88). However, ISD's inherently low decay efficiency greatly limits its application in proteomics. To increase the dissociation efficiency, various strategies were employed, including adjusting instrumental parameters such as laser intensity and ion extraction delay time, adding salt, and optimizing the matrix (89-92).

An improved understanding of the decay process may be helpful for developing a highly efficient ISD strategy. Although the decay process is commonly believed to be initiated by a reduction of

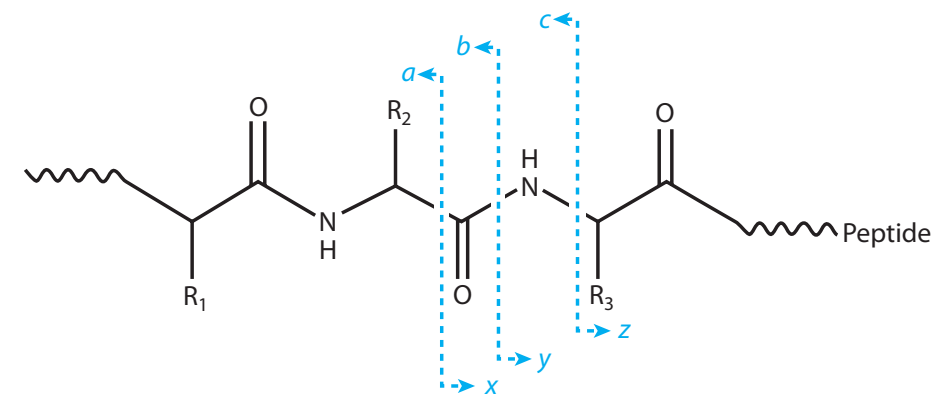

Figure 5
ECD: electroncapture dissociation

Peptide fragments. 
the carbonyl group of the peptide bond, there remains some debate as to whether it is due to an electron-transfer reaction or a hydrogen radical-transfer reaction (93, 94). Zenobi and coworkers (72) found that such a decay can be restricted in electron-free MALDI and suggested that it is a type of in-plume ECD. In 2005, Zubarev and colleagues (93) argued that ISD is not mediated by direct electron capture of peptides but rather from a hydrogen atom-transfer model. Given that the hydrogen radical is a product of the reaction between a free electron and a neutral matrix molecule (67), electron-induced in-plume reactions can still be observed.

\subsection{Matrix-Free Laser Desorption/Ionization}

As discussed above, the presence of matrix on a metallic target plate yields satisfactory results, but the reaction mechanisms are complex. Alternatively, semiconductor substrates such as silicon and $\mathrm{TiO}_{2}$ can be used to generate gas-phase ions, in which case the photoelectrochemical principles are easier to understand. Furthermore, matrix-free LDI methods are also useful for analysis of small molecules that cannot be observed in the presence of a matrix, as organic matrix clusters usually generate strong peaks in the low-mass region $(<1500 \mathrm{Da})(24)$. The DIOS approach is one of the most widely developed (24, 95-99), but semiconductors such as $\mathrm{TiO}_{2}(100,101)$, sol-gels (102), carbon-based polymers (103-105), and nanostructures (106) have also been successfully used.

In this section we discuss $\mathrm{TiO}_{2}$-modified target plates. When such plates are used, the laser energy is absorbed by the semiconductor structure, and electrons can be excited from the valence to the conduction band, generating oxidative holes and reductive electrons $(26,107,108)$. Some of these holes and electrons recombine either in the nanostructure or on its surface, thereby releasing heat energy to analytes. Alternatively, these electrons and holes can react with species near the substrate and induce on-plate redox reactions. In the presence of electron-donor molecules, oxidation can occur, and the electrons can migrate through the mesoporous semiconductor layer to the metallic substrate. In the presence of electron-acceptor molecules, reduction can occur, and again, the electrons may transfer from the metallic substrate through the porous semiconductor. In both cases, the $\mathrm{TiO}_{2}$-modified substrate can be considered as a photoelectrode (Figure 6). The electron mobility on sintered $\mathrm{TiO}_{2}$ nanoparticles is of the order of $10^{-6}-10^{-7} \mathrm{~cm}^{2} \mathrm{~V}^{-1} \mathrm{~s}^{1}$. The products of these electrode reactions can react in source with analytes to generate various ions either directly at the plate or in the plume. Parts of the ions can be extracted for analysis by the applied electric field according to their charge, and the counterions are driven back to the plate.

\subsection{In-Source Redox Reactions on Photoelectrodes}

In contrast to MALDI, in semiconductor-based LDI only very few free electrons are generated in the plume because of the large work function. Moreover, most of the photon energy generates excitons formed from oxidative holes in the valence band and reductive electrons in the conduction band, which in turn can react with sample species added on the substrate. The LDI in-source redox principle was first applied to the online tagging of cysteine-containing peptides (107); this principle is similar to that described above for ESI. In this study, the authors used hydroquinone as a tag molecule and deposited it, together with the sample peptides, on a nano- $\mathrm{TiO}_{2}$-formed substrate. Under laser illumination, valence-band holes were generated and then immediately scavenged by the hydroquinone, producing benzoquinone. Through the Michael addition, the benzoquinone subsequently formed a complex with a mercapto group on the cysteine residues; peptide-selective tagging was therefore achieved concomitantly with sample ionization. The oxidation of hydroquinone occurs directly at the surface of $\mathrm{TiO}_{2}$ shortly after laser irradiation, 


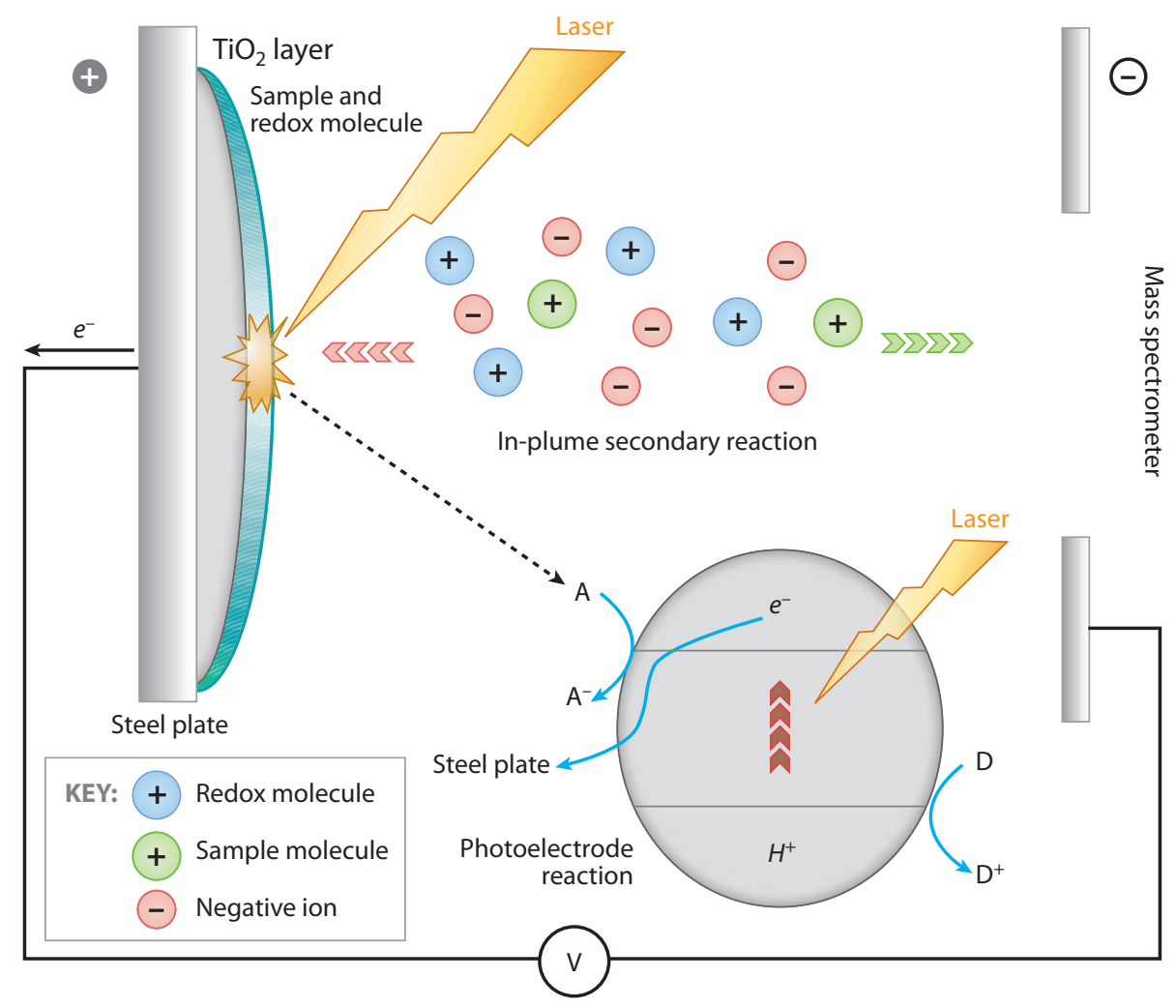

Figure 6

Schematic representation of a semiconductor-based laser desorption/ionization process, comprising a photoelectrode reaction and electron migration between a steel plate and a semiconductor layer, in positive-ionization mode. Abbreviations: A, electron acceptor; D, electron donor.

whereas the subsequent adduct formation occurs either at the plate surface or, as a secondary reaction, in the plume during the delayed ion-extraction time. During positive-ionization mode, because electrons in the conduction band can migrate into the steel plate under applied voltage, more holes are made available, thereby facilitating the oxidation of hydroquinone and further cysteine tagging.

As for the ESI online-tagging strategy, this semiconductor-based labeling method was shown to be specific and efficient for counting the number of cysteines in a peptide, thereby offering valuable supplementary information for use in the process of database interrogation for protein identification (109). Beta-lactoglobulin and bovine serum albumin (BSA) proteins were used to illustrate this principle. Following digestion and reduction of disulfide bonds, MALDI analysis, together with in-source cysteine tagging, was carried out for these samples. Four peptides of $\beta$-lactoglobulin and 19 peptides of BSA were tagged in source, and the cysteine residues were counted. When this additional information of cysteine content was taken into account, the database-searching scores for $\beta$-lactoglobulin and BSA were increased from 151 to 196 and 261 to 424, respectively, which will be of great importance in proteomics research. The authors also found that the substituted hydroquinones, including DHB, 2-methoxyhydroquinone, and dopamine, could also be used for a similar in-source photoelectrode-oxidation and cysteine-tagging experiment. 
Another interesting on-plate photooxidation reaction is peptide in-source fragmentation. An experiment investigating this reaction (26) was performed on $\mathrm{T}^{\mathrm{TiO}}{ }_{2}$ substrate, where samples were deposited with glucose in the absence of organic matrix on the semiconductor layer. Angiotensin I and oxidized $\beta$-insulin were used as standard samples to illustrate the phenomenon. As opposed to MALDI-ISD, which is a reduction process induced by electrons that normally generate $c$ - and $z$ fragments, peptide decay obtained through photooxidation on the $\mathrm{TiO}_{2}$ substrate yields intensive $a$ - and $x$-fragments (Figure 7).

Glucose, a hole scavenger (110), has been shown to act as a hole conductor. It is oxidized on the surface of a $\mathrm{TiO}_{2}$ photoelectrode by photoinitiated holes to form radicals via the loss of one hydrogen atom; this phenomenon has also been reported in classic photocatalysis reactions (110). The glucose radicals show a strong oxidative reactivity and react with one another or with the analytes, leading to long-distance oxidation on the plate or in the ionization plume. Indeed, it has been found that other hole scavengers, such as lactose, sucrose, galactal acid, glucal acid, citric acid, and hydroquinone, can also induce peptide-oxidative decay to generate $a$ - and $x$-fragments. Two mechanisms, including hydrogen-radical abstraction and electron transfer, both of which are based on the oxidation of amide nitrogen by glucose radical, have been proposed to account for this unusual fragmentation pattern (Figure 7a). The hydrogen-radical abstraction mechanism here is similar to that proposed for electron-detachment dissociation (111-113). Also, when the peptides come into direct contact with the semiconductor, electron migration between $\mathrm{TiO}_{2}$ and the sample becomes possible, which can result in both peptide-reductive dissociation of $c$ - and $z$-fragmentation and oxidative dissociation of $a$ - and $x$-fragmentation (Figure $7 \boldsymbol{b}$ ). Considering that the amount of glucose is much higher than the amount of peptides, the second outcome is less probable. Therefore, the products of ISD on $\mathrm{TiO}_{2}$ substrate would mainly show $a$ - and $x$-fragments. Specifically, when MS was run in positive-ionization mode, $a$-ions were observed almost exclusively, whereas when MS was run in negative-ionization mode, weak $c$-ion signals were observed as well. These results are in accordance with those observed following a steel plateelectrode reaction during high-voltage application. In positive-ionization mode, electrons were extracted from the conduction band of semiconductors to the steel plate; this left few electrons for reductive dissociation, resulting in a pattern of only $a$ - and $x$-fragmentation (Figure $7 a$ ) in what could be considered as a photoanodic reaction. In contrast, negative-ionization mode can benefit reductive dissociation somewhat by yielding $a$ - and $x$-fragmentation and $c$ - and $z$-dissociation (Figure $7 \boldsymbol{b}$ ) in what could be considered as a photocathodic reaction.

Electrons in the conduction band of semiconductor materials generated by laser irradiation have also been used for in-source reduction of small molecules such as $\mathrm{Cu}$ (II) and dyes. As in MALDI, reduction of $\mathrm{Cu}(\mathrm{II})$ and dyes have been observed in DIOS, and it is believed that the reduction is more prominent during DIOS than during MALDI $(74,114)$. In MALDI, reduction of dyes is significantly suppressed by the presence of $\mathrm{Cu}$ (II) ions, whereas no such effect is observed in the corresponding DIOS mass spectrum. Wada and colleagues (74) suggested that the required number of electrons in the conduction band could be supplied by the silicon substrate, which would render $\mathrm{Cu}(\mathrm{II})$ ion doping ineffective.

Another application of semiconductor-based in-source reductive reactions involves the cleavage of the disulfide bond, a typical reduction process employed in proteomics (86). Indeed, disulfidebond formation is a posttranslational modification that strongly stabilizes the three-dimensional structure of proteins, and its cleavage is necessary for the rapid sequencing of proteins containing such modifications (86). Traditional disulfide-profiling approaches require pretreatment strategies such as digestion, in-solution chemical reduction, and alkylation. Recently, Tanaka and colleagues (115) reported a new matrix, 1,5-diaminonaphthalene, to help in-source disulfide reduction for disulfide mapping, which is a MALDI in-plume reduction procedure. An alternative protocol 
a

b

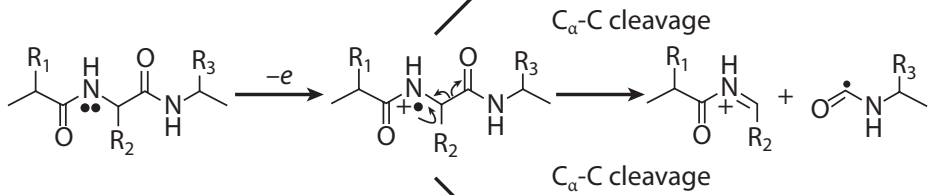

$-\mathrm{H} \cdot \mathrm{y}$<smiles>[R]C(CC)NC(=O)[14C]([2H])NC(=O)C([R])C</smiles>
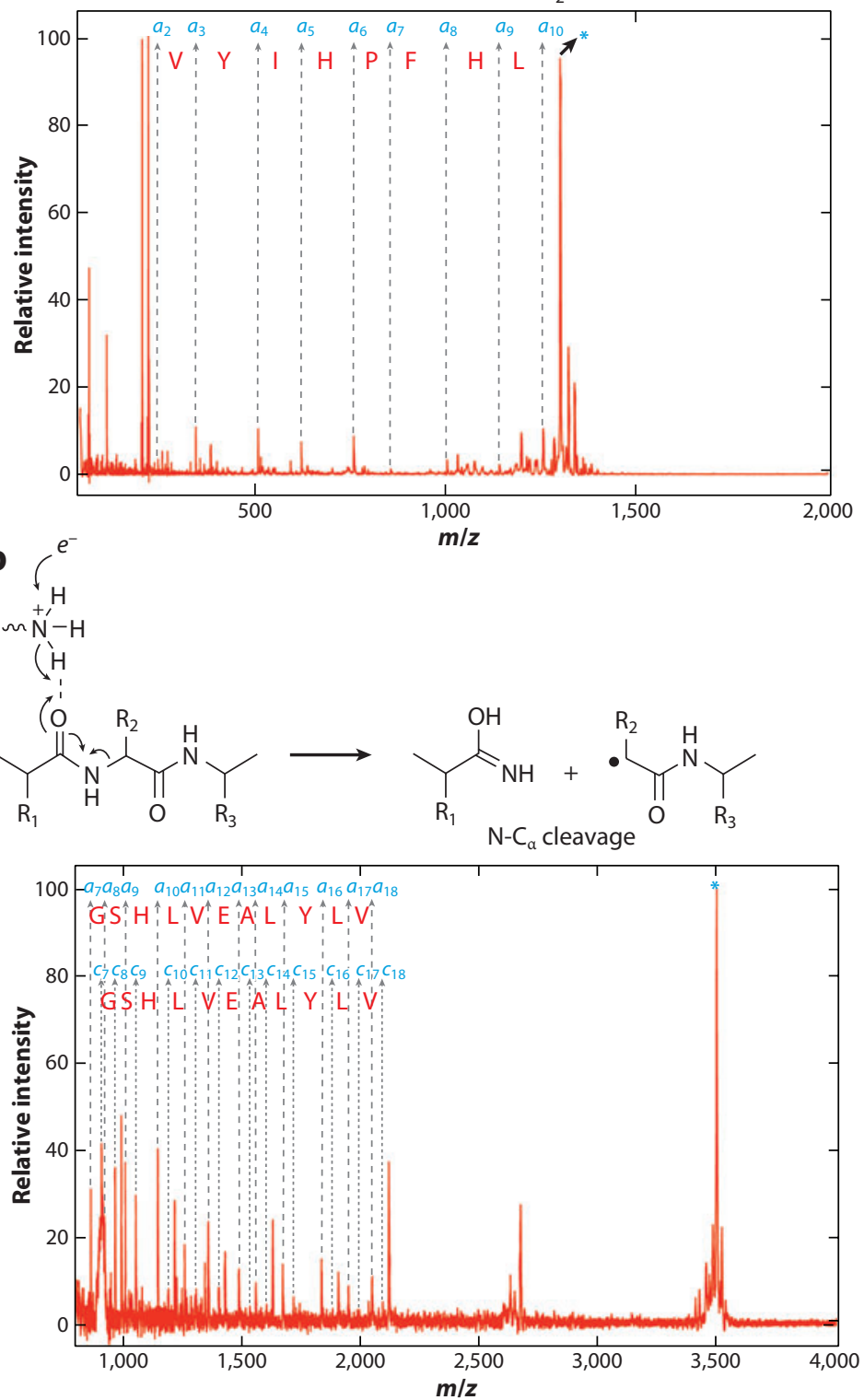

Figure 7

(a) Proposed mechanism for peptide-oxidative decay, and the fragmentation pattern of angiotensin I on a $\mathrm{TiO}_{2}$ substrate in the presence of glucose in positive-ionization mode. (b) Proposed mechanism for peptide-reductive decay, and the fragmentation pattern of oxidized $\beta$-insulin on a $\mathrm{TiO}_{2}$ substrate in the presence of glucose in negative-ionization mode. Abbreviations: asterisk, parent ion; $a_{x}$ and $c_{x}, a-$ and $c$-fragments. 
for matrix-free LDI was developed to realize the in-source cleavage of disulfide bonds; this approach involves depositing samples, together with glucose, onto a $\mathrm{TiO}_{2}$-modified plate (108). The reduction has been observed, although ionization is poor because matrix-free methods for large-molecule ionization are less efficient than MALDI methods.

\section{SUMMARY AND OUTLOOK}

In this review we have highlighted the different electrochemical aspects of both ESI and LDI. In many situations, and particularly when uncontrolled, the electrochemistry inherent to the electrospray process is detrimental to analysis. A complete understanding of the electrochemical reactions occurring at the electrospray electrode is therefore necessary and may be beneficial from an analytical viewpoint. Electrochemically enhanced analyte ionization, in situ electrochemical reactions, and sacrificial metallic anodes are good examples of analytical applications derived from the electrochemical aspects of the electrospray source.

Although the electrochemistry of LDI has been less widely studied, we have shown that, even for MALDI analysis, the target plates can be considered as photoelectrodes. In the case of mesoporous semiconductor-coated plates, we have shown that it is easier to control the photoelectrochemical reactions than during the typical MALDI process and that it is possible to carry out oxidation and reduction reactions in photoanodic and photocathodic processes, respectively.

\section{SUMMARY POINTS}

1. The continuous electrospray current in ESI-MS is maintained by heterogeneous reactions that occur at the emitter electrode.

2. Uncontrolled electrochemical reactions in ESI-MS may alter the solution; induce secondary, unwanted homogeneous reactions with analytes; and enhance ion-suppression effects.

3. Controlled electrochemical reactions in ESI-MS are utilized to enhance the ionization of neutral compounds or as online reactors and sacrificial metallic anodes.

4. LDI target plates work as electrodes during voltage application.

5. Electron-transfer reactions occur between the steel target plate and the semiconductor substrate or unextracted ions.

6. Photoinduced electron-transfer reactions occur in the plume generated by matrix ablation.

7. Inorganic semiconductor substrates can be used to carry out controllable photoelectrochemical reactions.

\section{FUTURE ISSUES}

1. We need to fully elucidate the electrochemical aspect of electrospray droplets and desorption ESI.

2. Further work is required to understand the fundamental mechanism of LDI.

3. Novel photosensitive materials will lead to new avenues for soft ionization. 
4. The electrochemical oxidation of biomolecules may be used as a tool to understand the effects of reactive oxygen species in vivo.

5. New voltage-pulse sequences must be tried to investigate on-plate reactions.

6. The mechanism of matrix-assisted laser desorption/ESI should be elucidated.

\section{DISCLOSURE STATEMENT}

The authors are not aware of any affiliations, memberships, funding, or financial holdings that might be perceived as affecting the objectivity of this review.

\section{ACKNOWLEDGMENT}

The authors wish to thank both the Swiss National Science Foundation for supporting our project (analytical tools for proteome analysis and redoxomics, 200020-127142) and the National Science Foundation of China (NSFC 20925517).

\section{LITERATURE CITED}

1. Hawkridge AM, Muddiman DC. 2009. Mass spectrometry-based biomarker discovery: toward a global proteome index of individuality. Annu. Rev. Anal. Chem. 2:265-77

2. Chang HC. 2009. Ultrahigh-mass mass spectrometry of single biomolecules and bioparticles. Annu. Rev. Anal. Chem. 2:169-85

3. Burnum KE, Frappier SL, Caprioli RM. 2008. Matrix-assisted laser desorption/ionization imaging mass spectrometry for the investigation of proteins and peptides. Annu. Rev. Anal. Chem. 1:689-705

4. Yamashita M, Fenn JB. 1984. Eelectrospray ion-source-another variation on the free-jet theme. F. Phys. Chem. 88:4451-59

5. Karas M, Bachmann D, Bahr U, Hillenkamp F. 1987. Matrix-assisted ultraviolet-laser desorption of nonvolatile compounds. Int. 7. Mass Spectrom. Ion Processes 78:53-68

6. Nollet JA. 1749. Recherches sur les causes particulières des phénomènes électriques. Paris: Chez les Frères Guerin. 1st ed.

7. Zeleny J. 1914. The electrical discharge from liquid points, and a hydrostatic method of measuring the electric intensity at their surfaces. Phys. Rev. 3:69-91

8. Dole M, Mack LL, Hines RL, Chemistry DO, Mobley RC, et al. 1968. Molecular beams of macroions. 7. Chem. Phys. 49:2240-49

9. Alexandrov ML, Gall LN, Krasnov NV, Nikolaev VI, Pavlenko VA, Shkurov VA. 1983. Short communication. Int. 7. Mass Spectrom. Ion Processes 54:231-35

10. Cole RB. 1997. Electrospray Ionization Mass Spectrometry: Fundamentals, Instrumentation and Applications. New York: Wiley

11. Kebarle P, Tang L. 1993. From ions in solution to ions in the gas phase: the mechanism of electrospray mass spectrometry. Anal. Chem. 65:972-86A

12. Kebarle P, Peschke M. 2000. On the mechanisms by which the charged droplets produced by electrospray lead to gas phase ions. Anal. Chim. Acta 406:11-35

13. Kebarle P. 2000. A brief overview of the present status of the mechanisms involved in electrospray mass spectrometry. 7. Mass Spectrom. 35:804-17

14. Cole RB. 2000. Some tenets pertaining to electrospray ionization mass spectrometry. 7. Mass Spectrom. 35:763-72

15. Cech NB, Enke CG. 2001. Practical implications of some recent studies in electrospray ionization fundamentals. Mass Spectrom. Rev. 20:362-87 
16. Mora J, Van Berkel GJ, Enke C, Cole R, Martinez-Sanchez M, Fenn JB. 2000. Electrochemical processes in electrospray ionization mass spectrometry. 7. Mass Spectrom. 35:939-52

17. Van Berkel GJ, Kertesz V. 2007. Using the electrochemistry of the electrospray ion source. Anal. Chem. 79:5510-20

18. Permentier HP, Bruins AP, Bischoff R. 2008. Electrochemistry-mass spectrometry in drug metabolism and protein research. Mini Rev. Med. Chem. 8:46-56

19. Karst U. 2004. Electrochemistry/mass spectrometry (EC/MS) — a new tool to study drug metabolism and reaction mechanisms. Angew. Chem. Int. Ed. 43:2476-78

20. Diehl G, Karst U. 2002. On-line electrochemistry - MS and related techniques. Anal. Bioanal. Chem. 373:390-98

21. Tanaka K, Waki H, Ido Y, Akita S, Yoshida Y, et al. 1988. Protein and polymer analyses up to $\mathrm{m} / \mathrm{z}$ 100,000 by laser ionization time-of-flight mass spectrometry. Rapid Commun. Mass Spectrom. 2:151-53

22. Stump MJ, Fleming RC, Gong WH, Jaber AJ, Jones JJ, et al. 2002. Matrix-assisted laser desorption mass spectrometry. Appl. Spectrosc. Rev. 37:275-303

23. Wei J, Buriak JM, Siuzdak G. 1999. Desorption-ionization mass spectrometry on porous silicon. Nature 399:243-46

24. Peterson DS. 2007. Matrix-free methods for laser desorption/ionization mass spectrometry. Mass Spectrom. Rev. 26:19-34

25. Karas M, Kruger R. 2003. Ion formation in MALDI: the cluster ionization mechanism. Chem. Rev. 103:427-39

26. Qiao L, Bi HY, Busnel JM, Waser J, Yang PY, et al. 2009. Photocatalytic redox reactions for in-source peptide fragmentation. Chem. A Eur. 7. 15:6711-17

27. Taylor GI. 1964. Disintegration of water drops in an electric field. Proc. R. Soc. London Ser. A 280:383-97

28. Eyring CF, MacKeown SS, Millikan RA. 1928. Fields currents from points. Phys. Rev. 31:900-9

29. Girault HH. 2004. Electrified interfaces. In Analytical and Physical Chemistry, pp. 177-220. Lausanne: EPFL

30. Mack LL, Kralik P, Rheude A, Dole M. 1970. Molecular beams of macroions. II. 7. Chem. Phys. 52:497786

31. Iribarne JV, Thomson BA. 1976. On the evaporation of small ions from charged droplets. F. Chem. Phys. 64:2287-94

32. Marcus RA. 2000. On the theory of ion transfer rates across the interface of two immiscible liquids. 7. Chem. Phys. 113:1618-29

33. Blades AT, Ikonomou MG, Kebarle P. 1991. Mechanism of electrospray mass spectrometry. Electrospray as an electrolysis cell. Anal. Chem. 63:2109-14

34. Jackson G, Enke C. 1999. Electrical equivalence of electrospray ionization with conducting and nonconducting needles. Anal. Chem. 71:3777-84

35. Van Berkel GJ, Zhou F. 1995. Characterization of an electrospray ion source as a controlled-current electrolytic cell. Anal. Chem. 67:2916-23

36. Van Berkel GJ, Zhou F, Aronson JT. 1997. Changes in bulk solution pH caused by the inherent controlled-current electrolytic process of an electrospray ion source. Int. 7. Mass Spectrom. Ion Processes $162: 55-67$

37. Konermann L, Silva EA, Sogbein OF. 2001. Electrochemically induced $\mathrm{pH}$ changes resulting in protein unfolding in the ion source of an electrospray mass spectrometer. Anal. Chem. 73:4836-44

38. Pan P, Gunawardena HP, Xia Y, McLuckey SA. 2004. Nanoelectrospray ionization of protein mixtures: solution $\mathrm{pH}$ and protein pI. Anal. Chem. 76:1165-74

39. Van Berkel GJ, McLuckey SA, Glish GL. 1992. Electrochemical origin of radical cations observed in electrospray ionization mass spectra. Anal. Chem. 64:1586-93

40. Xu X, Nolan SP, Cole RB. 1994. Electrochemical oxidation and nucleophilic addition reactions of metallocenes in electrospray mass spectrometry. Anal. Chem. 66:119-25

41. Ochran R, Konermann L. 2004. Effects of ground loop currents on signal intensities in electrospray mass spectrometry. 7. Am. Soc. Mass Spectrom. 15:1748-54

42. Rohner TC, Rossier JS, Girault HH. 2002. On-line electrochemical tagging of cysteines in proteins during nanospray. Electrochem. Commun. 4:695-700 
43. Roussel C, Dayon L, Lion N, Rohner TC, Josserand J, et al. 2004. Generation of mass tags by the inherent electrochemistry of electrospray for protein mass spectrometry. 7. Am. Soc. Mass Spectrom. 15:1767-79

44. Dayon L, Josserand J, Girault HH. 2005. Electrochemical multi-tagging of cysteinyl peptides during microspray mass spectrometry: numerical simulation of consecutive reactions in a microchannel. Phys. Chem. Chem. Phys. 7:4054-60

45. Dayon L, Roussel C, Prudent M, Lion N, Girault HH. 2005. On-line counting of cysteine residues in peptides during electrospray ionization by electrogenerated tags and their application to protein identification. Electrophoresis 26:238-47

46. Dayon L, Roussel C, Girault HH. 2006. Probing cysteine reactivity in proteins by mass spectrometric EC-tagging. 7. Proteome Res. 5:793-800

47. Van Berkel GJ, Kertesz V. 2009. Electrochemically initiated tagging of thiols using an electrospray ionization based liquid microjunction surface sampling probe two-electrode cell. Rapid Commun. Mass Spectrom. 23:1380-86

48. Van Berkel GJ. 1998. Electrolytic corrosion of a stainless-steel electrospray emitter monitored using an electrospray-photodiode array system. F. Anal. At. Spectrom. 13:603-7

49. Van Berkel GJ, Asano KG, Schnier PD. 2001. Electrochemical processes in a wire-in-a-capillary bulkloaded, nano-electrospray emitter. F. Am. Soc. Mass Spectrom. 12:853-62

50. Van Berkel GJ, Kertesz V. 2001. Redox buffering in an electrospray ion source using a copper capillary emitter. 7. Mass Spectrom. 36:1125-32

51. Mirza UA, Chalt BT. 1994. Effects of anions on the positive ion electrospray ionization mass spectra of peptides and proteins. Anal. Chem. 66:2898-904

52. Enke CG. 1997. A predictive model for matrix and analyte effects in electrospray ionization of singlycharged ionic analytes. Anal. Chem. 69:4885-93

53. Rohner TC, Girault HH. 2005. Study of peptide on-line complexation with transition-metal ions generated from sacrificial electrodes in thin-chip polymer microsprays. Rapid Commun. Mass Spectrom. 19:118390

54. Prudent M, Roussel C, Girault HH. 2007. Electrochemical generation of $\mathrm{Cu}(\mathrm{I})$ complexes in aqueous solutions studied by on-line mass spectrometry. Electrochem. Commun. 9:2067-74

55. Prudent M, Girault HH. 2008. On-line electrogeneration of copper-peptide complexes in microspray mass spectrometry. 7. Am. Soc. Mass Spectrom. 19:560-68

56. Prudent M, Rossier JS, Lion N, Girault HH. 2008. Microfabricated dual sprayer for on-line mass tagging of phosphopeptides. Anal. Chem. 80:2531-38

57. Kertesz V, Van Berkel GJ. 2006. Expanded use of a battery-powered two-electrode emitter cell for electrospray mass spectrometry. 7. Am. Soc. Mass Spectrom. 17:953-61

58. Xu X, Lu W, Cole RB. 1996. On-line probe for fast electrochemistry/electrospray mass spectrometry. Investigation of polycyclic aromatic hydrocarbons. Anal. Chem. 68:4244-53

59. Van Berkel GJ, Asano KG, Granger MC. 2004. Controlling analyte electrochemistry in an electrospray ion source with a three-electrode emitter cell. Anal. Chem. 76:1493-99

60. Kertesz V, Van Berkel GJ, Granger MC. 2005. Study and application of a controlled-potential electrochemistry-electrospray emitter for electrospray mass spectrometry. Anal. Chem. 77:4366-73

61. Liu BH, Lee YT, Wang YS. 2009. Incoherent production reactions of positive and negative ions in matrix-assisted laser desorption/ionization. 7. Am. Soc. Mass Spectrom. 20:1078-86

62. Karas M, Gluckmann M, Schafer J. 2000. Ionization in matrix-assisted laser desorption/ionization: Singly charged molecular ions are the lucky survivors. 7. Mass Spectrom. 35:1-12

63. Lehmann E, Knochenmuss R, Zenobi R. 1997. Ionization mechanisms in matrix-assisted laser desorption ionization mass spectrometry: contribution of preformed ions. Rapid Commun. Mass Spectrom. 11:1483-92

64. Sarver A, Scheffler NK, Shetlar MD, Gibson BW. 2001. Analysis of peptides and proteins containing nitrotyrosine by matrix-assisted laser desorption/ionization mass spectrometry. F. Am. Soc. Mass Spectrom. $12: 439-48$

65. Petersson AS, Steen H, Kalume DE, Caidahl K, Roepstorff P. 2001. Investigation of tyrosine nitration in proteins by mass spectrometry. 7. Mass Spectrom. 36:616-25 
66. Kaneko R, Wada Y. 2003. Decomposition of protein nitrosothiols in matrix-assisted laser desorption/ionization and electrospray ionization mass spectrometry. 7. Mass Spectrom. 38:526-30

67. Frankevich VE, Zhang J, Friess SD, Dashtiev M, Zenobi R. 2003. Role of electrons in laser desorption/ionization mass spectrometry. Anal. Chem. 75:6063-67

68. Frankevich V, Knochenmuss R, Zenobi R. 2002. The origin of electrons in MALDI and their use for sympathetic cooling of negative ions in FTICR. Int. 7. Mass Spectrom. 220:11-19

69. Gorshkov MV, Frankevich VE, Zenobi R. 2002. Characteristics of photoelectrons emitted in matrixassisted laser desorption/ionization Fourier transform ion cyclotron resonance experiments. Eur. F. Mass Spectrom. 8:67-69

70. Knochenmuss R, McCombie G, Faderl M. 2006. Ion yields of thin MALDI samples: dependence on matrix and metal substrate and implications for models. 7. Phys. Chem. A 110:12728-33

71. Gruszecka A, Szymanska-Chargot M, Smolira A, Cytawa J, Michalak L. 2008. Role of the support material on laser desorption/ionization mass spectra. Rapid Commun. Mass Spectrom. 22:925-29

72. Frankevich V, Zhang J, Dashtiev M, Zenobi R. 2003. Production and fragmentation of multiply charged ions in 'electron-free' matrix-assisted laser desorption/ionization. Rapid Commun. Mass Spectrom. 17:2343-48

73. Zhang J, Frankevich V, Knochenmuss R, Friess SD, Zenobi R. 2003. Reduction of Cu(II) in matrixassisted laser desorption/ionization mass spectrometry. 7. Am. Soc. Mass Spectrom. 14:42-50

74. Okuno S, Nakano M, Matsubayashi G, Arakawa R, Wada Y. 2004. Reduction of organic dyes in matrixassisted laser desorption/ionization and desorption/ionization on porous silicon. Rapid Commun. Mass Spectrom. 18:2811-17

75. Brown RS, Lennon JJ. 1995. Sequence-specific fragmentation of matrix-assisted laser-desorbed protein peptide ions. Anal. Chem. 67:3990-99

76. Yalcin T, Schriemer DC, Li L. 1997. Matrix-assisted laser desorption ionization time-of-flight mass spectrometry for the analysis of polydienes. 7. Am. Soc. Mass Spectrom. 8:1220-29

77. Wong CKL, Chan TWD. 1997. Cationization processes in matrix-assisted laser desorption/ionization mass spectrometry: attachment of divalent and trivalent metal ions. Rapid Commun. Mass Spectrom. 11:513-19

78. Masselon C, Salih B, Zenobi R. 1999. Matrix-assisted laser desorption/ionization Fourier transform mass spectrometry of luteinizing hormone releasing hormone-metal ion complexes. 7. Am. Soc. Mass Spectrom. 10:19-26

79. Lavanant H, Hoppilliard Y. 1997. Formation and fragmentation of $\alpha$-amino acids complexed by $\mathrm{Cu}^{+}$. 7. Mass Spectrom. 32:1037-49

80. Salih B, Masselon C, Zenobi R. 1998. Matrix-assisted laser desorption/ionization mass spectrometry of noncovalent protein transition metal ion complexes. 7. Mass Spectrom. 33:994-1002

81. Kosevich MV, Chagovets VV, Shmigol IV, Snegir SV, Boryak OA, et al. 2008. Sensitivity of redox reactions of dyes to variations of conditions created in mass spectrometric experiments. F. Mass Spectrom. 43:1402-12

82. Sachon E, Clodic G, Blasco T, Bolbach G. 2007. Protein desolvation in UV matrix-assisted laser desorption/ionization (MALDI). F. Am. Soc. Mass Spectrom. 18:1880-90

83. Hardouin J. 2007. Protein sequence information by matrix-assisted laser desorption/ionization in-source decay mass spectrometry. Mass Spectrom. Rev. 26:672-82

84. Demeure K, Quinton L, Gabelica V, De Pauw E. 2007. Rational selection of the optimum MALDI matrix for top-down proteomics by in-source decay. Anal. Chem. 79:8678-85

85. Gao JL, Tsugita A, Takayama M, Xu L. 2002. A programmable fragmentation analysis of proteins by in-source decay in MALDI-TOF mass spectrometry. Anal. Chem. 74:1449-57

86. Schnaible V, Wefing S, Resemann A, Suckau D, Bucker A, et al. 2002. Screening for disulfide bonds in proteins by MALDI in-source decay and LIFT-TOF/TOF-MS. Anal. Chem. 74:4980-88

87. Reiber DC, Grover TA, Brown RS. 1998. Identifying proteins using matrix-assisted laser desorption/ionization in-source fragmentation data combined with database searching. Anal. Chem. 70:673-83

88. Takayama M. 2001. In-source decay characteristics of peptides in matrix-assisted laser desorption/ionization time-of-flight mass spectrometry. F. Am. Soc. Mass Spectrom. 12:420-27 
89. Brown RS, Carr BL, Lennon JJ. 1996. Factors that influence the observed fast fragmentation of peptides in matrix-assisted laser desorption. 7. Am. Soc. Mass Spectrom. 7:225-32

90. Brown RS, Feng JH, Reiber DC. 1997. Further studies of in-source fragmentation of peptides in matrixassisted laser desorption-ionization. Int. F. Mass Spectrom. 169:1-18

91. Marzilli LA, Golden TR, Cotter RJ, Woods AS. 2000. Peptide sequence information derived by pronase digestion and ammonium sulfate in-source decay matrix-assisted laser desorption/ionization time-offlight mass spectrometry. 7. Am. Soc. Mass Spectrom. 11:1000-8

92. Katta V, Chow DT, Rohde MF. 1998. Applications of in-source fragmentation of protein ions for direct sequence analysis by delayed extraction MALDI-TOF mass spectrometry. Anal. Chem. 70:4410-16

93. Kocher T, Engstrom A, Zubarev RA. 2005. Fragmentation of peptides in MALDI in-source decay mediated by hydrogen radicals. Anal. Chem. 77:172-77

94. Takayama M. 2001. N-C- $\alpha$ bond cleavage of the peptide backbone via hydrogen abstraction. 7. Am. Soc. Mass Spectrom. 12:1044-49

95. Go EP, Apon JV, Luo G, Saghatelian A, Daniels RH, et al. 2005. Desorption/ionization on silicon nanowires. Anal. Chem. 77:1641-46

96. Trauger SA, Go EP, Shen ZX, Apon JV, Compton BJ, et al. 2004. High sensitivity and analyte capture with desorption/ionization mass spectrometry on silylated porous silicon. Anal. Chem. 76:4484-89

97. Lewis WG, Shen ZX, Finn MG, Siuzdak G. 2003. Desorption/ionization on silicon (DIOS) mass spectrometry: background and applications. Int. 7. Mass Spectrom. 226:107-16

98. Shen ZX, Thomas JJ, Averbuj C, Broo KM, Engelhard M, et al. 2001. Porous silicon as a versatile platform for laser desorption/ionization mass spectrometry. Anal. Chem. 73:612-19

99. Thomas JJ, Shen ZX, Crowell JE, Finn MG, Siuzdak G. 2001. Desorption/ionization on silicon (DIOS): a diverse mass spectrometry platform for protein characterization. Proc. Natl. Acad. Sci. USA 98:493237

100. Chen CT, Chen YC. 2004. Molecularly imprinted $\mathrm{TiO}_{2}$-matrix-assisted laser desorption/ionization mass spectrometry for selectively detecting $\alpha$-cyclodextrin. Anal. Chem. 76:1453-57

101. Chen CT, Chen YC. 2004. Desorption/ionization mass spectrometry on nanocrystalline titania sol-geldeposited films. Rapid Commun. Mass Spectrom. 18:1956-64

102. Lin YS, Chen YC. 2002. Laser desorption/ionization time-of-flight mass spectrometry on sol-gel-derived 2,5-dihydroxybenzoic acid film. Anal. Chem. 74:5793-98

103. Sunner J, Dratz E, Chen YC. 1995. Graphite surface assisted laser desorption/ionization time-of-flight mass spectrometry of prptides and proteins from liquid solutions. Anal. Chem. 67:4335-42

104. Chen YC, Shiea J, Sunner J. 1998. Thin-layer chromatography mass spectrometry using activated carbon, surface-assisted laser desorption/ionization. F. Chromatogr. A 826:77-86

105. Han M, Sunner J. 2000. An activated carbon substrate surface for laser desorption mass spectrometry. 7. Am. Soc. Mass Spectrom. 11:644-49

106. Xu SY, Li YF, Zou HF, Qiu JS, Guo Z, Guo BC. 2003. Carbon nanotubes as assisted matrix for laser desorption/ionization time-of-flight mass spectrometry. Anal. Chem. 75:6191-95

107. Qiao L, Roussel C, Wan JJ, Kong J, Yang PY, et al. 2008. MALDI in-source photooxidation reactions for online peptide tagging. Angew. Chem. Int. Ed. 47:2646-48

108. Qiao L, Bi HY, Busnel JM, Liu BH, Girault HH. 2008. In-source photocatalytic reduction of disulfide bonds during laser desorption ionization. Chem. Commun. 2008:6357-59

109. Sechi S, Chait BT. 1998. Modification of cysteine residues by alkylation. A tool in peptide mapping and protein identification. Anal. Chem. 70:5150-58

110. Shkrob IA, Sauer MC, Gosztola D. 2004. Efficient, rapid photooxidation of chemisorbed polyhydroxyl alcohols and carbohydrates by $\mathrm{TiO}_{2}$ nanoparticles in an aqueous solution. F. Phys. Chem. B 108:1251217

111. Kjeldsen F, Silivra OA, Ivonin IA, Haselmann KF, Gorshkov M, Zubarev RA. 2005. C- $\alpha$-C backbone fragmentation dominates in electron detachment dissociation of gas-phase polypeptide polyanions. Chem. Eur. 7. 11:1803-12

112. Haselmann KF, Budnik BA, Kjeldsen F, Nielsen ML, Olsen JV, Zubarev RA. 2002. Electronic excitation gives informative fragmentation of polypeptide cations and anions. Eur. 7. Mass Spectrom. 8:117-21 
113. Budnik BA, Haselmann KF, Zubarev RA. 2001. Electron detachment dissociation of peptide di-anions: an electron-hole recombination phenomenon. Chem. Phys. Lett. 342:299-302

114. Okuno S, Arakawa R, Wada Y. 2004. Reduction of $\mathrm{Cu}(\mathrm{II})$ and riboflavin in DIOS mass spectrometry. 7. Mass Spectrom. Soc. 7pn. 52:13-20

115. Fukuyama Y, Iwamoto S, Tanaka K. 2006. Rapid sequencing and disulfide mapping of peptides containing disulfide bonds by using 1,5-diaminonaphthalene as a reductive matrix. 7. Mass Spectrom. 41:191-201 


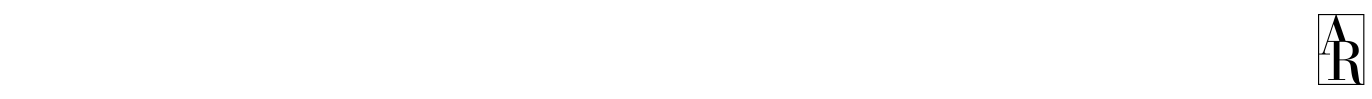

\section{Contents}

Annual Review of Analytical Chemistry

Volume 3, 2010

An Editor's View of Analytical Chemistry (the Discipline)

Royce W. Murray ........................................................... 1

Integrated Microreactors for Reaction Automation: New Approaches

to Reaction Development

Fonatban P. McMullen and Klavs F. Fensen .....................................19

Ambient Ionization Mass Spectrometry

Min-Zong Huang, Cheng-Hui Yuan, Sy-Chyi Cheng, Yi-Tzu Cho, and Fentaie Shiea

Evaluation of DNA/Ligand Interactions by Electrospray Ionization

Mass Spectrometry

Fennifer S. Brodbelt

Analysis of Water in Confined Geometries and at Interfaces

Michael D. Fayer and Nancy E. Levinger

Single-Molecule DNA Analysis

7. William Efcavitch and Fobn F. Thompson

Capillary Liquid Chromatography at Ultrahigh Pressures

Fames $W$. Forgenson

In Situ Optical Studies of Solid-Oxide Fuel Cells

Michael B. Pomfret, Jeffrey C. Owrutsky, and Robert A. Walker

Cavity-Enhanced Direct Frequency Comb Spectroscopy: Technology and Applications

Florian Adler, Michael 7. Thorpe, Kevin C. Cossel, and Jun Ye

Electrochemical Impedance Spectroscopy Byoung-Yong Chang and Su-Moon Park

Electrochemical Aspects of Electrospray and Laser

Desorption/Ionization for Mass Spectrometry

Mélanie Abonnenc, Liang Qiao, BaoHong Liu, and Hubert H. Girault ... 
Adaptive Microsensor Systems

Ricardo Gutierrez-Osuna and Andreas Hierlemann 255

Confocal Raman Microscopy of Optical-Trapped Particles in Liquids Daniel P. Cherney and Foel M. Harris

Scanning Electrochemical Microscopy in Neuroscience Albert Schulte, Michaela Nebel, and Wolfgang Scbubmann

Single-Biomolecule Kinetics: The Art of Studying a Single Enzyme

Victor I. Claessen, Hans Engelkamp, Peter C.M. Christianen, Fan C. Maan, Roeland 7.M. Nolte, Kerstin Blank, and Alan E. Rowan

Chiral Separations

A.M. Stalcup

Gas-Phase Chemistry of Multiply Charged Bioions in Analytical Mass Spectrometry Teng-Yi Huang and Scott A. McLuckey 365

Rotationally Induced Hydrodynamics: Fundamentals and Applications to High-Speed Bioassays Gufeng Wang, Jeremy D. Driskell, April A. Hill, Eric 7. Dufek, Robert 7. Lipert, and Marc D. Porter 387

Microsystems for the Capture of Low-Abundance Cells Udara Dharmasiri, Matgorzata A. Witek, Andre A. Adams, and Steven A. Soper

Advances in Mass Spectrometry for Lipidomics Stephen 7. Blanksby and Todd W. Mitchell...

\section{Indexes}

Cumulative Index of Contributing Authors, Volumes 1-3 ...................... 467

Cumulative Index of Chapter Titles, Volumes 1-3 ............................ 470

\section{Errata}

An online log of corrections to Annual Review of Analytical Chemistry articles may be found at http://arjournals.annualreviews.org/errata/anchem. 